\title{
KOMPOISI JENIS DAN STRUKTUR KOMUNITAS IKAN PADANG LAMUN DI PERAIRAN PANTAI LATERI TELUK AMBON DALAM
}

\author{
Husain Latuconsina \\ Staf Pengajar FPIK UNIDAR-Ambon, $\boldsymbol{e}$-mail: husainlatuconsina@ymail.com
}

\begin{abstract}
ABSTRAK
Penelitian dilaksanakan pada bulan Maret 2011 di perairan pantai Lateri Teluk Ambon Bagian Dalam (TAD), yang bertujuan untuk mengetahui komposisi jenis dan struktur komunitas ikan pada ekosistem padang lamun. Dalam penelitian ini terkoleksi sebanyak 288 individu dari 31 jenis dan 19 famili. Kenyataan ini menunjukkan bahwa ekosistem padang lamun TAD memiliki potensi sumberdaya hayati ikan yang tinggi. Dengan komposisi jenis tertinggi dari jenis Syngnathoides biaculeatus yang dikenal sebagai ikan penetap atau ikan khas padang lamun. Nilai Indeks Dominansi 0,11 dan Indeks Keanekaragaman dengan kriteria sedang yaitu 2,59 serta Indeks Keseragaman 0,76 menunjukkan bahwa secara ekologi tidak terdapat spesies yang mendominasi dan struktur komunitas dalam kondisi stabil. Sehingga diperlukan upaya pengelolaan dan konservasi untuk mempertahankan kestabilan komunitas ikan beserta peranan ekologi ekosistem padang lamun sebagai tempat mencari makan, memijah, dan pembesaran bagi komunitas ikan.
\end{abstract}

\section{Kata Kunci: Padang lamun, komunitas ikan, perairan pantai lestari}

\section{PENDAHULUAN}

\subsection{Latar Belakang}

Salah satu ekosistem pesisir yang mempunyai produktivitas primer tinggi yaitu padang lamun (seagrass bads) yang merupakan jenis tanaman berbunga dan sudah menyesuaikan diri untuk hidup terendam dalam air laut, menyebabkan pola penyerbukan berlangsung dengan perantara air. Tingginya produktivitas primer pada ekosistem padang lamun menjadikannya sebagai tempat mencari makan (feeding ground), memijah (spawning ground), pembesaran (nursery ground), dan tempat berlindung bagi sebagian besar sumberdaya hayati ikan (Supriharyono, 2007).

Massa daun lamun akan menurunkan pencahayaan pada siang hari, melindungi dasar perairan dari isolasi dan memungkinkan pengembangan lingkungan mikro pada dasar vegetasi. Keadaan ini akan menguntungkan bagi fauna di padang lamun. Disamping itu, padang lamun merupakan habitat bagi juvenil ikan karena dapat berfungsi sebagai tempat berlindung atau mencari makan. Beberapa jenis ikan juga meletakan telurnya dan mejadikan padang lamun sebagai tempat memijah (Aswandy dan Azkab, 2000).
Salah satu kawasan yang memiliki potensi padang lamun di Indonesia adalah perairan peisir Teluk Ambon bagian Dalam (TAD) yang merupakan perairan dangkal dengan kisaran kedalaman 0-40 $\mathrm{m}$ dan dipisahkan oleh ambang yang sempit dengan kedalaman hanya $12 \mathrm{~m}$, menyebabkan sirkulasi masa air tidak berjalan lancar (Mudjiono,2008).

Pemukiman penduduk yang semakin padat, terutama di wilayah pesisir, kondisi topografi daratan yang memiliki kemiringan relatif terjal, aktifitas pembukaan lahan atas untuk berbagai kepentingan, seperti ; pemukiman, pelabuhan, perikanan (keramba) dan arus lalu lintas laut yang semakin padat akan berdampak pada tekanan ekologis yang semakin tinggi terhadap perairan Teluk Ambon. Konsekwensi tersebut menyebabkan perubahan kualitas perairan di Teluk Ambon bagian Dalam (TAD) dan pada akhirnya akan merusak ekosistem yang ada di perairan tersebut, termasuk ekosistem lamun yang akan diikuti menurunnya keanekaragaman sumberdaya ikan yang hidup di dalamnya.

Untuk itu, pengetahuan terkini tentang komposisi jenis dan struktur komunitas ikan pada eksosistem padang lamun merupakan informasi 
penting dalam upaya pengelolaan dan konservasi ekosistem padang lamun agar dapat mempertahankan fungsi ekologisnya sebagai tempat mencari makan, memijah dan pembesaran bagi komunitas ikan yang berasosiasi di dalamnya.

\subsection{Tujuan dan Manfaat Penelitian :}

Penelitian ini bertujuan untuk mengetahui komposisi jenis dan struktur komunitas ikan pada ekosistem padang lamun di perairan pantai Lateri Teluk Ambon Dalam (TAD).
Manfaat dari penelitian ini adalah sebagai bahan informasi ilmiah terkait peranan ekologis eksosistem padang lamun bagi sumberdaya hayati ikan, sebagai dasar pengelolaan dan upaya konservasi ekosistem padang lamun.

\section{METODE PENELITIAN}

\subsection{Lokasi dan Waktu}

Penelitian dilaksanakan pada bulan Maret 2011 pada ekosistem padang lamun di perairan pantai Lateri - Teluk Ambon bagian Dalam (TAD) (Gambar 1).

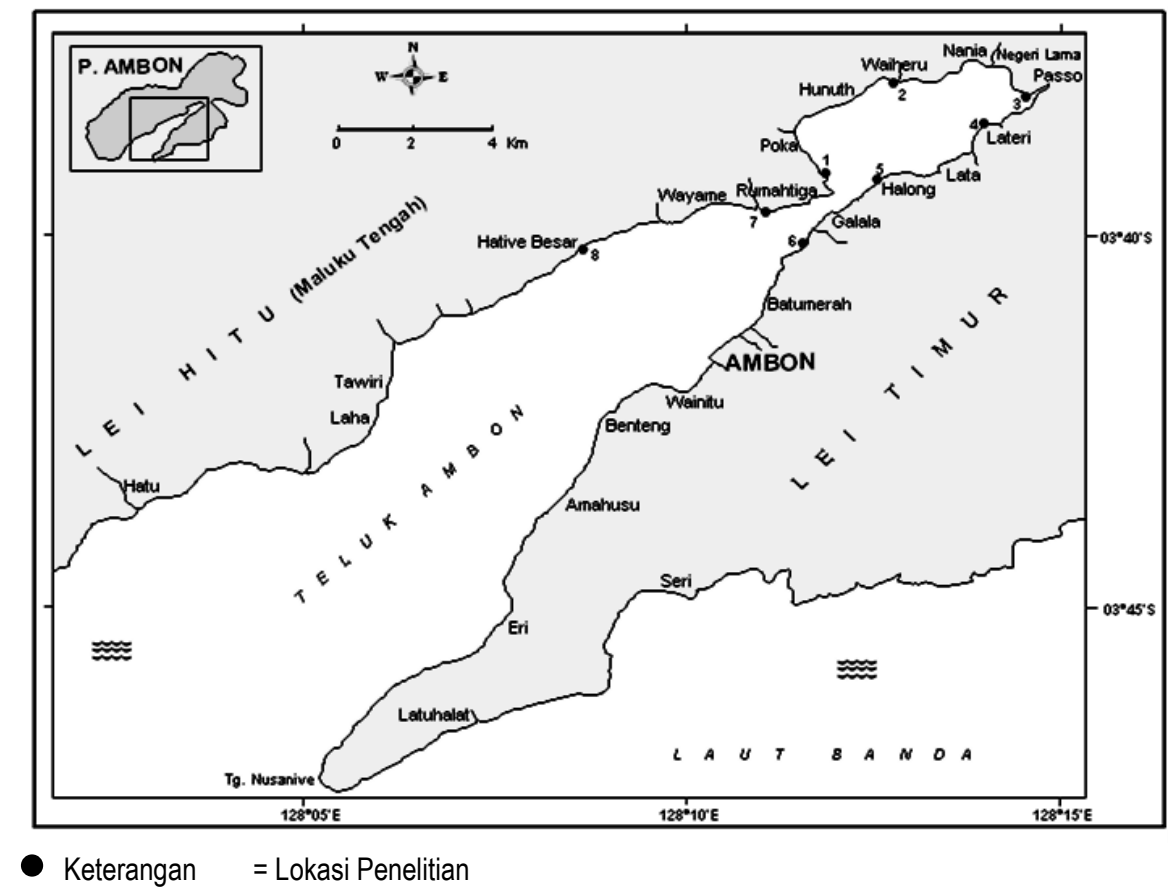

Gambar 1. Peta Lokasi Penelitian di Teluk Ambon Bagian Dalam

\subsection{Pengukuran Perairan \\ Parameter \\ Lingkungan}

Parameter lingkungan perairan diamati, meliputi: Salinitas, Suhu, $\mathrm{pH}$, dan Oksigen terlarut (DO) dan kekeruhan diukur secara insitu.

\subsection{Teknik Sampling Komunitas Ikan}

Data komunitas ikan dikoleksi dengan menggunakan Pukat Pantai (Beach seine) yang ditarik pada hamparan padang lamun sebanyak 3 kali. Ikan yang tertangkap ditempatkan pada kantong plastik yang diberi label dan dimasukan dalam cold box kemudian diidentifikasi jenis, dihitung jumlah dan ditimbang beratnya. Identifikasi jenis ikan menurut Allen (199), Carpenter \& Niem (1999 \& 2001) Kuiter \& Tonozuka (2001) dan Peristiwady (2006).

\subsection{Analisa Data}

\subsubsection{Komposisi Jenis}

Untuk mengetahui komposisi jenis ikan menggunakan formula :

$$
K j=\frac{n i}{N} \times 100 \%
$$

Dimana: $\mathrm{Kj}=$ Komposisi jenis ikan (\%), $\mathrm{ni}=$ Jumlah individu setiap jenis ikan, $\mathrm{N}=$ Jumlah individu seluruh jenis ikan

\subsubsection{Struktur Komunitas}

Struktur komunitas ikan dapat diketahui dengan menggunakan beberapa Indeks Ekologi dalam (Fachrul, 2007, Setyobudiandi et al, 2009 dan Khouw, 2009).

1. Indeks Dominansi :

$$
C=\sum\left(\frac{n i}{N}\right)^{2}
$$


Dimana :

$\mathrm{C}=$ Indeks Dominansi Simpson

ni $=$ Jumlah individu dari jenis ke-i

$\mathrm{N}=$ Jumlah total individu seluruh jenis

Nilai indeks Dominansi (C) antara

0 - 0,50 menunjukkan dominansi rendah,

$>0,50-0,75$ menunjukkan dominansi sedang dan $>0,75-1,00$ Dominansinya tinggi.

\section{Indeks Keanekaragaman Jenis :}

$$
\mathrm{H}^{\prime}=-\sum P i \ln (P i)
$$

Dimana :

$\mathrm{H}^{\prime}=$ Indeks Keanekaragaman Shannon-Wiener,

$P i=$ Proporsi jumlah individu (ni/N)

Nilai indeks Keankearagaman $\left(\mathrm{H}^{\prime}\right)>3$ menunjukkan keanekaragaman tinggi, antara 1-3 keanekaragaman sedang dan $<1$ menunjukkan keanekaragaman rendah.

3. Indeks Ekuitabilitas (Keseragaman):

$$
\mathrm{E}=\frac{\mathrm{H}^{\prime}}{\log \mathrm{S}}
$$

Dimana:

$$
\begin{aligned}
& \mathrm{E}=\text { Indeks Keseragaman } \\
& \mathrm{H}^{\prime}=\text { Keanekaragaman Shannon-Wiener } \\
& \mathrm{S}=\text { Jumlah jenis/spesies, }
\end{aligned}
$$

Nilai indeks Keseragaman (E) antara 0 0,50 menunjukkan keseragaman rendah, $>0,50-$ 0,75 menunjukkan keseragaman sedang, dan > $0,75-1,00$ menunjukkan keseragaman tinggi.

\section{Indeks Biologi}

Penentuan ikan-ikan yang memiliki peranan penting dalam struktur komunitas menggunakan Indeks Biologi dengan cara memberikan nilai berdasarkan pada jumlah individu satu jenis ikan yang tertangkap. Spesies yang memiliki jumlah individu terbanyak diberi nilai 10 berikutnya diberi nilai 9 dan seterusnya. Indeks biologi masing-masing spesies menunjukkan nilai penting spesies tersebut dalam komunitas.

\section{HASIL DAN PEMBAHASAN \\ 3.1. Kondisi Habitat Lamun.}

Komunitas padang lamun yang ditemukan pada perairan Teluk Ambon Dalam khususnya perairan pantai Lateri yang letaknya di sebelah Timur, pada posisi $03^{\circ} 38^{\prime} 51,3^{\prime}$ ' LS dan $128^{\circ}$ 13' 55,4' BT dengan karakteristik substrat pecahan karang, pasir sampai lumpur. Ditemukan 2 jenis lamun, yaitu ; Enhalus acoroides dan Thalassia hemprichii, tumbuh $\pm 30 \mathrm{~m}$ dari tepi pantai dengan panjang zonasi lebih dari $100 \mathrm{~m}$.

\subsection{Kondisi Parameter Kualitas Air}

Hasil pengukuran beberapa parameter lingkungan perairan yang diperkirakan mempengerahui distribusi dan kelimpahan komunitas ikan pada ekosistem padang lamun terlihat pada Tabel 1. Berdasarkan hasil pengukuran parameter kualitas air semuanya masih dalam kondisi (nilai) optimal yang dibutuhkan oleh ikan untuk tumbuh dan berkembang.

Tabel 1. Hasil Pengukuran Parameter Fisika-kimia Perairan

\begin{tabular}{ccccc}
\hline Suhu $\left({ }^{\circ} \mathrm{C}\right)$ & Salinitas $(\%)$ & $\mathrm{pH}$ & DO $(\mathrm{mg} / \mathrm{l})$ & Kekeruhan (NTU) \\
\hline 31,20 & 33,30 & 8,01 & 6,51 & 2,10 \\
\hline
\end{tabular}

Nilai Suhu perairan yang diamati $31,20^{\circ} \mathrm{C}$, kisaran ini masih merupakan kisaran optimal bagi kehidupan ikan. Menurut Kordi dan Tancung (2007) bahwa kisaran suhu optimal bagi kehidupan ikan di perairan tropis adalah antara $28^{\circ} \mathrm{C}-32^{\circ} \mathrm{C}$. Dimana suhu perairan mempengaruhi aktivitas metabolisme ikan dan sangat berkaitan erat dengan oksigen terlarut dan konsumsi oksigen oleh ikan. Sementara itu menurut Suyasa et al (2010) dapat merangsang syaraf dan aktivitas hidup ikan yang merupakan tipe hewan berdarah dingin sehingga temperature tubuhnya tidak dapat diatur secara internal, tetapi menyesuaikan diri dengan suhu lingkungan disekitarnya

Untuk nilai salinitas sebesar 33,30\%, dan masih merupakan kisaran optimal air laut yaitu $30 \%$ - 40\%o, dimana salinitas air berpengaruh terhadap tekanan osmotik air, dan semakin tinggi salinitas akan semakin besar tekanan osmotiknya yang berpengaruh terhadap biota perairan (Kordi dan Tancung, 2007).

Nilai $\mathrm{pH}$ perairan pada semua stasiun pengamatan masih optimal bagi kehidupan ikan. Dimana menurut Kordi dan Tancung (2007) nilai pH 6,5 - 9,0 merupakan kisaran pH optimal bagi pertumbuhan ikan. $\mathrm{pH}$ air mempengaruhi tingkat 
kesuburan perairan karena mempengaruhi kehidupan jasad renik. Perairan yang asam akan kurang produktif karena kandungan oksigen terlarutnya rendah, yang berakibat aktivitas pernafasan ikan meningkat dan nafsu makan menurun. Nilai Oksigen terlarut (DO) yang diamati sebesar $6,51 \mathrm{mg} / 1$ masih optimal bagi pertumbuhan ikan. Dimana menurut Boyd (1995) kisaran oksigen terlarut yang optimal bagi pertumbuhan ikan adalah di atas $5 \mathrm{mg} / \mathrm{l}$ sampai batas konpensasi.

\subsection{Komposisi Jenis, Jumlah Individu dan Nilai Penting}

Dari hasil penangkapan menggunakan Pukat Pantai (Beach seine), berhasil dikoleksi total jumlah ikan sebanyak 288 individu melipti 31 jenis dari 19 famili (Tabel 2). Berdasarkan Tabel 2 terlihat komposisi jenis tertinggi adalah dari jenis Syngnathoides biaculeatus sebesar 22,57 \% dengan jumlah 65 individu, sementara komposisi jenis terbesar kedua adalah Aeoliscus strigatus dengan nilai komposisi jenis 17,71\% dan jumlah 51 individu. Tingginya komposisi jenis dari kedua spesies ini dikarenakan merupakan ikan penghuni tetap pada eksosistem padang lamun dan ditemukan dengan berbagai struktur ukuran yang merepresentasekan tingkatan umur yang bervariasi.

Jumlah individu dan biomas ikan-ikan dominan yang memiliki nilai penting pada ekosistem padang lamun di perairan pantai Lateri (Gambar 2).

Tabel 2. Komposisi Jenis Ikan padang Lamun perairan Lateri

\begin{tabular}{|c|c|c|c|}
\hline FAMILI & SPESIES & $\begin{array}{c}\text { Jumlah } \\
\text { Ekor }\end{array}$ & $\begin{array}{c}\text { Komposisi } \\
\text { Jenis (\%) }\end{array}$ \\
\hline BLENNIDAE & Petroscirtes variabilis (Cantor,1850) & 4 & 1.39 \\
\hline BOTHIDAE & Bothus pantherinus (Rüppell, 1830) & 1 & 0.35 \\
\hline CARANGIDAE & Caranx sexfasciatus (Quoy \& Gaimard, 1825) & 2 & 0.69 \\
\hline CENTRICIDAE & Aeoliscus strigatus (Günther, 1860) & 51 & 17.71 \\
\hline FISTULARIDAE & Fistularia petimba Lacepède, 1803 & 7 & 2.43 \\
\hline \multirow[t]{2}{*}{ GERREIDAE } & Gerres oyena (Forsskål, 1775) & 1 & 0.35 \\
\hline & Choerodon anchorago (Bloch, 1791) & 1 & 0.35 \\
\hline \multirow{3}{*}{ LABRIDAE } & Halichoeres chloropterus (Bloch, 1791) & 2 & 0.69 \\
\hline & Halichoeres melanurus (Bleeker, 1851) & 1 & 0.35 \\
\hline & Halichoeres scapularis (Bennett, 1831) & 1 & 0.35 \\
\hline LUTJANIDAE & Lutjanus fulviflamma (Forsskål, 1775) & 2 & 0.69 \\
\hline \multirow[t]{2}{*}{ MONACANTHIDAE } & Acriecthys tomentosus (Linaeus, 1758) & 15 & 5.21 \\
\hline & Mulloidichthys vanicolensis (Valenciennes, 1831) & 1 & 0.35 \\
\hline \multirow[t]{2}{*}{ MULLIDAE } & Parupeneus barberinus (Lacepède, 1801) & 27 & 9.38 \\
\hline & Upeneus tragula (Richardson, 1846) & 12 & 4.17 \\
\hline \multirow{2}{*}{ NEMIPTERIDAE } & Pentapodus trivittatus (Bloch, 1791) & 2 & 0.69 \\
\hline & Scolopsis ciliata (Lacepède, 1802) & 9 & 3.13 \\
\hline SCARIDAE & Scarus sp & 1 & 0.35 \\
\hline SERRANIDAE & Epinephelus maculatus (Bloch, 1790) & 1 & 0.35 \\
\hline \multirow[t]{3}{*}{ SYNGNATHIDAE } & Syngnathoides biaculeatus (Bloch, 1785) & 65 & 22.57 \\
\hline & Inimicus didactylus (Pallas,1769) & 3 & 1.04 \\
\hline & Paracentropogon longispinis (Cuvier, 1829) & 17 & 5.90 \\
\hline \multirow[t]{3}{*}{ SCORPAENIDAE } & Pterois volitans (Linnaeus, 1758) & 1 & 0.35 \\
\hline & Scorpaenopsis sp & 3 & 1.04 \\
\hline & Scorpaenopsis venosa (Cuvier, 1829) & 1 & 0.35 \\
\hline SIGANIDAE & Siganus canaliculatus (Park, 1797) & 15 & 5.21 \\
\hline \multirow[t]{2}{*}{ SYNODONTIDAE } & Saurida gracilis (Quoy \& Gaimard, 1824) & 28 & 9.72 \\
\hline & Arothron manilenis (Marion de Procé, 1822) & 6 & 2.08 \\
\hline \multirow[t]{2}{*}{ TETRAODONTIDAE } & Arothron reticularis (Bloch \& Schneider, 1801) & 1 & 0.35 \\
\hline & Chelonodon patoca (Buchanan, 1822) & 3 & 1.04 \\
\hline \multirow[t]{2}{*}{ PLATYCEPHALIDAE } & Platycephalus indicus (Linnaeus, 1758) & 4 & 1.39 \\
\hline & 31 & 288 & 100.00 \\
\hline
\end{tabular}




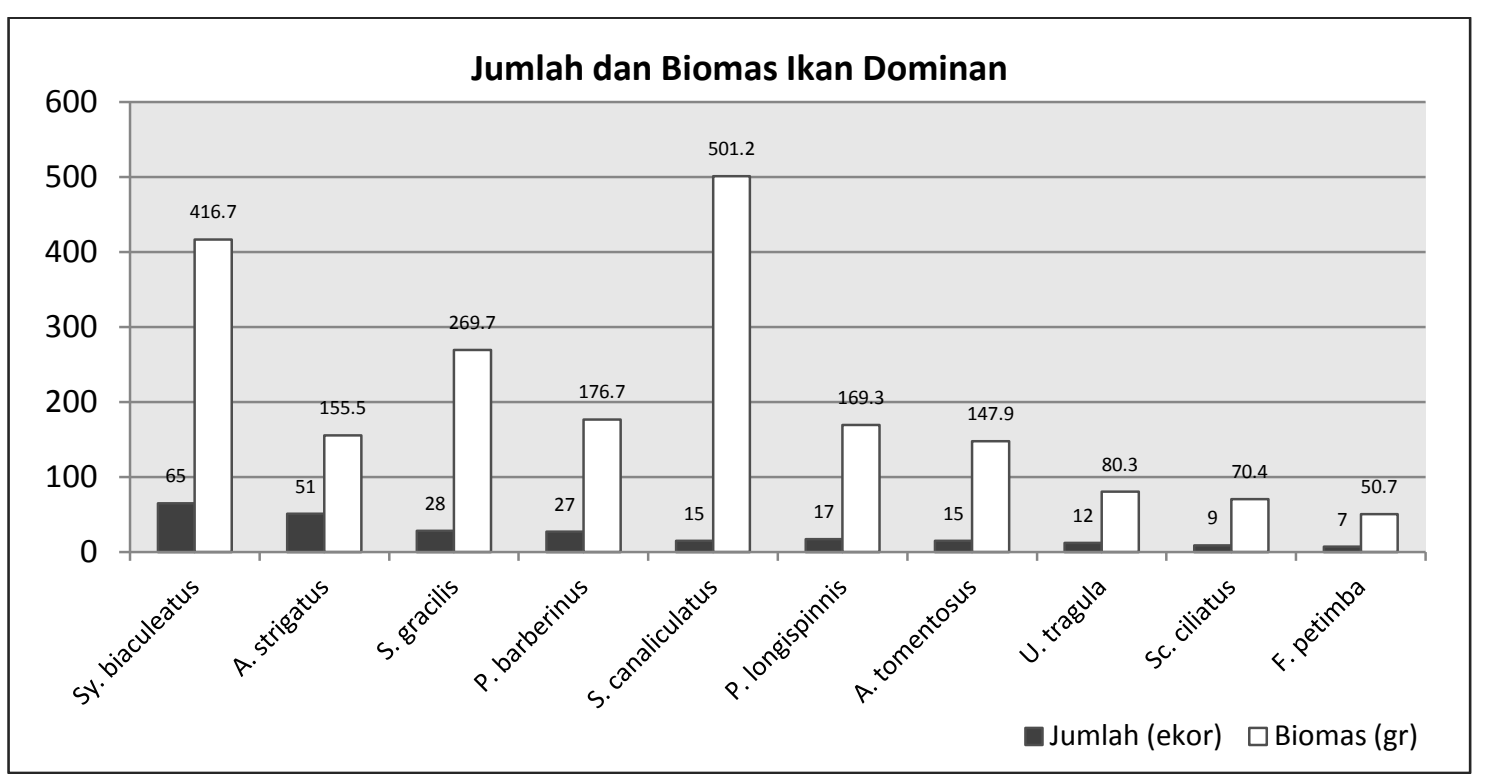

Gambar 2. Jumlah Individu dan Biomas Ikan dominan yang memiliki nilai penting dalam struktur komunitas pada Teluk Ambon bagian Dalam.

Berdasarkan Gambar 3, menunjukkan bahwa banyaknya jumlah individu suatu jenis ikan yang tertangkap tidak menjamin tingginya biomas ikan tersebut karena bobot ikan yang bervariasi menurut jenis dan ukuran tubuhnya. Misalnya jumlah individu terbesar yang didapatkan dari jenis Synangthoides biaculeatus sebanyak 65 individu, sementara biomas tertinggi dari jenis Siganus canaliculatus sebesar 501,2 gram.

Dari 10 besar ikan yang tertangkap (Gambar 3) 4 jenis diduga merupakan penghuni tetap berdasarkan struktur ukuran yang bervariasi yaitu : Synangthoides biaculeatus, Aeoliscus strigatus, Acriecthys tomentosus dan Paracentropogon longispinis, selebihnya merupakan ikan yang menjadikan padang lamun sebagai daerah pembesaran seperti Siganus canaliculatus, Saurida gracilis, Parupeneus barberinus, Upeneus tragula, Scolopsis ciliata dan Fistularia petimba karena hanya ditemukan dalam ukuran juvenil. Fenomena ini menunjukkan bahwa ekosistem padang lamun secara ekologi sebagai tempat perlindungan dan mencari makan bagi komunitas ikan pada sebagian fase / siklus hidupnya, sehingga ikanikan yang bersifat menetap sementara pada ekosistem padang lamun mendominasi dan mempengaruhi struktur komunitas.

\subsection{Struktur Komunitas Ikan}

Hasil analisa struktur komunitas ikan yang meliputi Indeks Dominansi, Keanekaragaman
Jenis, dan Indeks Keseragaman seperti terlihat pada Tabel 2.

Tabel 2. Struktur Komunitas Ikan padang Lamun di Perairan Teluk Ambon Dalam

\begin{tabular}{lc}
\hline \multicolumn{1}{c}{ Struktur Komunitas } & Nilai \\
\hline Indeks Dominansi (c) & 0.11 \\
Indeks Keanekaragaman (H') & 2.59 \\
Indeks Keseragaman (E) & 0.76 \\
\hline
\end{tabular}

Dari hasil analisa data struktur komunitas ikan (Tabel 2), terlihat bahwa secara ekologi tidak terdapat ikan yang dominan karena indeks dominansinya rendah dengan nilai mendekati 0 . Rendahnya nilai indeks Dominansi ini berbanding terbalik dengan nilai Indeks Keanekaragaman Jenis dengan kriteria sedang sebesar 2,59, dan indeks keseragaman yang tinggi dengan nilai 0,76 .

Menurut Brower et al (1990), keanekaragaman jenis adalah suatu ekspresi dari struktur komunitas, dimana suatu komunitas dikatakan memiliki keanekaragaman jenis tinggi, jika proporsi antar jenis secara keseluruhan sama banyak. Sehingga jika ada beberapa jenis dalam komunitas yang memiliki kelimpahan atau dominansi yang besar maka Keanekaragamannya dan keseragamannya rendah. Dengan demikian tidak terdapat ikan dengan dominansi yang besar yang berarti struktur komunitas masih dalam kondisi stabil. 


\section{PENUTUP}

\subsection{Kesimpulan}

1. Hasil penelitian terkoleksi sebanyak 288 individu dari 31 jenis dan 19 famili dari keseluruhan ikan yang ditemukan sebagian besar merupakan ikan-ikan dengan ukuran juvenil. Hanya ditemukan 4 spesies dengan berbagai ukuran yaitu: Aeoliscus strigatus, Acriecthys tomentosus, Synangthoides biaculeatus dan Paracentropogon longispinis. Artinya ekosistem padang lamun di perairan pantai Lateri Teluk Ambon Dalam memiliki peranan ekologis sebagai daerah pemijahan, tempat asuhan dan pembesaran, serta tempat berlindung bagi komunitas ikan di perairan pesisir.

2. Komposisi jenis terbesar adalah jenis Synangthoides biaculeatus dan Aeoliscus strigatus yang diketahui sebagai penghuni tetap pada ekosistem padang lamun.

3. Nilai Indeks Dominansi yang rendah mendekati 0,11 dan Indeks Keanekaragaman sebesar 2,59 dengan kriteria sedang serta Indeks Keseragaman sebesar 0,76 dengan kriteria tinggi, menunjukkan bahwa secara ekologi tidak terdapat spesies yang mendominasi sehingga struktur komunitas masih dalam kondisi stabil.

\subsection{Saran}

1. Diperlukan pengamatan komunitas ikan selama 1 tahun dalam setiap bulan yang mewakili 4 musim, untuk melihat secara menyeluruh potensi sumberdaya hayati ikan pada eksosistem padang lamun di perairan pantai Lateri Teluk Ambon bagian Dalam, karena diperkirakan masih banyak jenis ikan yang belum terkoleksi, mengingat komunitas ikan pada ekosistem padang lamun juga terdistribusi secara musiman dan dipengaruhi oleh fluktuasi parameter fisika dan kimia lingkungan perairan.

2. Diperlukan upaya konservasi untuk dapat mempertahankan peranan ekologis ekosistem padang lamun sebagai tempat mencari makan, memijah dan pembesaran bagi komunitas ikan di perairan laut dangkal, khusunya pada perairan pantai Lateri teluk Ambon Dalam (TAD).

\section{DAFTAR PUSATAKA}

Allen, G. 1999. Marine Fishes of South-East Asia; A guide for anglers and divers. Periplus Editions. Singapore.

Aswandy, I dan M.H.Azkab. 2000. Hubungan Fauna dengan Padang Lamun. Oseana. Volume XXV. No. $3: 19-24$.

Brower,J.E., J.H. Zar and C.N. Von Ende. 1990. Field and Laboratory Methods for General Ecology. Wim. C. Brown Co. Pub.Dubuque. Iowa.

Boyd,C.E. 1979. Water Quality in Warmwater Fish Ponds. Aurburn University, Alabama, USA.

Carpenter, K.E. and V.H. Niem. 1999. The Living marine Resources of the Western Central Pacific. Volume 3. Batoid fishes, chimaeras and bony fishes part 1 (Elopidae to Linophrynidae). FAO Species Indentification Guide For Fishery Purposes. Food and Agriculture of the United Nations. Rome.

Carpenter, K.E. and V.H. Niem. 1999. The Living marine Resources of the Western Central Pacific. Volume 4 : Bony fishes part 2 (Mugilidae to Carangidae). FAO Species Indentification Guide For Fishery Purposes. Food and Agriculture of the United Nations. Rome.

Carpenter, K.E. and V.H. Niem. 2001. The Living marine Resources of the Western Central Pacific. Volume 5. Bony fishes part 3 (Menidae to Pomacentridae). FAO Species Indentification. Food and Agriculture of the United Nations. Rome.

Carpenter, K.E. and V.H. Niem. 2001. The Living marine Resources of the Western Central Pacific. Volume 6 : Bony fishes part 4 (Labridae to Latimeriidae), estuarine crocodiles, sea turtles, sea snakes and marine mammals. FAO Species Indentification. Food and Agriculture of the United Nations. Rome.

Fachrul, M. F. 2007. Metode Sampling Bioekologi. Penerbit: Bumi Aksara. Jakarta.

Hutomo, M. 1985. Telaah Ekologi Komunitas Ikan padang Lamun (Seagrass, Anthophyta) di Perairan Teluk Banten. Disertasi. IPB. Bogor.

Khouw, A.S. 2009. Metode dan Analisa Kuantitatif dalam Bioekologi Laut. Pusat Pembelajaran dan Pengembangan Pesisir dan Laut (P4L), Ambon. 
Kuiter, R.H dan T, Tonozuka. 2001. Indonesian Reef Fishes. Part 1. Eels to Snappers: Murainidae to Lutjanidae. Zoonetic,Melbourne. Australia.

Kuiter, R.H dan T, Tonozuka. 2001. Indonesian Reef Fishes. Part 2. Fusiliers to Dragonets. : Caesionidae to Callyonimidae. Zoonetic,Melbourne. Australia.

Kuiter, R.H dan T, Tonozuka. 2001. Indonesian Reef Fishes. Part 3. Jawfishes-Sunfishes. Zoonetic,Melbourne. Australia.

Kordi, M.G.H dan A. Tancung. 2007. Pengelolaan Kualitas Air Dalam Budidaya Perairan. Rineka Cipta. Jakarta.

Manik, N dan A. Syahailatua. 1997. Sturktur Komunitas Ikan Padang Lamun Teluk Ambon Dalam. Prosiding Seminar Kelautan LIPI-UNHAS. Ambon. 133-139.

Mudjiono. 2008. Monitoring Teluk Ambon. Balai Konservasi Biota laut Ambon. Pusat Penelitian Oseanografi. Lembaga Ilmu Pengetahuan Indonesia (LIPI).Ambon.

Peristiwady, T. 2006. Ikan-Ikan Laut Ekonomis Penting di Indonesia; Petunjuk Identifikasi. LIPI press. Jakarta.

Setyobudiandi, I., Sulistiono., F. Yulianda., C.Kusmana,C.,S.Hariyadi.,A.Damar., A.Sembiring dan Bahtiar. 2009. Sampling dan Analisis Data Perikanan dan Kelautan; Terapan Metode Pengambilan Contoh di Wilayah Pesisir dan Laut. Fakultas Perikanan dan Ilmu Kelautan.IPB.Bogor.

Suyasa, I.N., N. Nurhudah dan S. Rahardjo. 2010. Ekologi Perairan. STP press. Jakarta.

Supriharyono, 2007. Konservasi Sumberdaya Hayati di Wilayah Pesisir Tropis. Pustaka Pelajar. Yogjakarta. 